\title{
Evaluation of Adenosine deaminase, Serum C-reactive protein and alkaline phosphatase activity in Rheumatoid Arthritis patients in Shivamogga district, South India
}

\author{
Sridevi V. ${ }^{1}$, Chandrakanth ${ }^{2}$, Vinit Anand ${ }^{3, *}$ \\ Professor, ${ }^{1,2}$ Dept. of Biochemistry, ${ }^{3}$ Dept. of Pathology, Subbaiah Institute of Medical Sciences, Shivamogga, \\ India
}

*Corresponding Author:

Email: srivinny4@gmail.com

\begin{abstract}
Introduction \& Objectives: Rheumatoid arthritis (RA) is a prototypical inflammatory joint disease. The degree of inflammation is reflected in the extent of joint damage, which further has influence on the quality of life of patients with RA. Serum adenosine deaminase (ADA) has been previously proposed to predict disease activity in patients with RA. The aim of this study was to investigate the level of serum ADA, CRP \& ALP in Rheumatoid arthritis patients and compare it with healthy subjects.

Materials and Methods: Fifty four RA patients and fifty four age matched healthy controls between 35-65 years were included in the study. ADA \&ALP activity and CRP levels in serum were measured in all the subjects and correlated.

Results: Serum ADA level was found significantly higher among RA subjects with respect to controls $(31.37 \pm 4.16$ versus $11.19 \pm 1.802 \mathrm{U} / \mathrm{L} ; \mathrm{P}<0.0001)$. Serum ALP levels were also increased in RA cases as compared to controls and were statistically significant $(145.17 \pm 15.86$ versus $83.19 \pm 17.55 \mathrm{U} / \mathrm{L}$; $\mathrm{P}<0.0001)$. Serum CRP levels were also increased among RA subjects when compared to controls $(2.60 \pm 1.16$ versus $0.283 \pm 0.1161)$.

Conclusion: ADA assay can be a reliable, sensitive and specific test. CRP is an important inflammatory marker for rapid diagnosis of rheumatoid arthritis. Increase in ALP in RA patients when compared to healthy controls suggests the role of serum ALP as a marker of disease activity in RA. However, larger and well controlled studies are needed to establish its role as inflammatory marker.
\end{abstract}

Keywords: Adenosine deaminase, Alkaline phosphatase, C-reactive protein, Rheumatoid arthritis.

Received: $08^{\text {th }}$ August, 2017

\section{Introduction}

Rheumatoid arthritis (RA) is a systemic autoimmune disorder causing chronic inflammation and proliferation of the synovial tissues, destruction of articular cartilage and also affects many other sites that include the heart, blood vessels and skin. ${ }^{1}$

In general population the prevalence of RA is believed to range from $0.5-1.0 \%{ }^{2} \mathrm{RA}$ is reported to affect almost $1 \%$ of adult population worldwide and approximately $0.75 \%$ of adult Indian population. ${ }^{3}$ In India alone there are some 10 million people with RA. ${ }^{4}$

Diagnosis of RA is done on the basis of clinical and radiological findings and presence of rheumatoid factor in serum. The characteristic feature of RA is non-specific inflammation of the peripheral joints with joint swelling, morning stiffness, destruction of articular tissues and joint deformities. ${ }^{5}$ The classification of RA is done by a score based algorithm system according to the 2010 ACR-EULAR classification criteria for rheumatoid arthritis. ${ }^{6,7}$
Accepted: $20^{\text {th }}$ November, 2017

Purine metabolism may be related to rheumatoid arthritis since several disturbances of purine metabolism have been found to be associated with immune disorders. ${ }^{8}$ Immune deregulation forms one of the pathogenic mechanisms of rheumatoid arthritis and hence, it is not surprising to find altered levels of purine enzymes in RA. Adenosine deaminase (ADA, adenosine amino hydrolase E.C. 3.5.4.4) is an important enzyme of purine metabolism catalysing the irreversible deamination of adenosine to form inosine ${ }^{9}$ and is considered as a marker of cell mediated immunity. ${ }^{4}$ Serum ADA was found to reflect monocyte / macrophage activity in inflammatory conditions such as RA and has also been suggested as a marker of inflammatory processes in RA. ${ }^{10}$ It is wellknown that continued disease activity results in joint damage, decreased physical activity or even irreversible disability. ${ }^{11}$ Hence, early diagnosis and intervention help in reducing the morbidity associated with RA.

CRP an acute phase protein is synthesized by hepatocytes in response to pro inflammatory 
cytokines in particular IL-6. ${ }^{4}$ It has been shown to be of great value as an inflammatory marker in RA and has been suggested to mediate part of the complement activation in RA. ${ }^{12}$

In rheumatoid arthritis the promotion of disease activity induces more active bone resorption. ${ }^{13}$ Activated bone resorption is accompanied by concomitant bone formation and a rise in serum ALP. ${ }^{14}$ Serum ALP may also be induced by inflammatory markers such as Interleukin-1 because it correlates with acute phase response. ${ }^{15}$

Therefore the present study was undertaken to estimate the serum ADA, a marker for cell mediated immunity and C-reactive protein a marker for inflammation and ALP in Shivamogga patients with RA. The objective was to assess the diagnostic potential of serum ADA activity for routine diagnosis of RA.

\section{Materials and Methods}

This study was conducted in Subbaiah Institute of Medical Sciences between January and July 2017. A total of fifty four patients diagnosed with Rheumatoid Arthritis without any medication and fifty four healthy controls aged between 35-65 years were included in the study. Informed consent was obtained from each subject. Ethical approval for the study was obtained from the Institutional research ethical committee.

Inclusion criteria: All the patients included in this study fulfilled the criteria of American Rheumatism Association. ${ }^{16}$

Presence of synovitis in at least one joint was considered. Patients with synovitis more than 6 weeks duration ware included. Patients with elevated ESR, positive Rheumatoid factor \& CRP were included in the study.

Exclusion criteria: RA patients with Tuberculosis, Diabetes Mellitus, Cardiovascular diseases, HIV/AIDS and patients with other types of musculoskeletal disorders, osteoarthritis, osteoporosis, spinal disorders, severe limb trauma and gouty arthritis were excluded from the study.
Sample Collection: Taking aseptic precautions, after an overnight fast of 10-12 hours, $5 \mathrm{ml}$ of venous blood was collected in plain Vacutainer [BD Biosciences] from antecubital vein from each patient. Serum separated from clotted blood was analyzed immediately for ADA activity, CRP, RF and ALP at central laboratory of Subbaiah Institute of Medical Sciences.

Serum ADA activity was measured using Adenosine deaminase assay kit (Erba Mannheim reagent kits obtained from Transasia BioMedicals) based on enzymatic deamination of adenosine to inosine which is converted to hypoxanthine by purine nucleoside phosphorylase. Hypoxanthine is then converted to uric acid and $\mathrm{H}_{2} \mathrm{O}_{2}$ by xanthine oxidase. $\mathrm{H}_{2} \mathrm{O}_{2}$ is further reacted with N-Ethyl-N-(2-hydroxy-3sulfopropyl)-3-methylaniline and 4- amino antipyrine in the presence of peroxidase to generate quinone dye which is monitered at $546 \mathrm{~nm}$. One unit of ADA is defined as the amount of ADA that generates $1 \mu$ mole of inosine from adenosine per $\min$ at $37^{\circ} \mathrm{C}$. Analysis was done on Robonik Brietest Biochem Analyser.

CRP \& RF were estimated by Immuno turbidometric Assay on Turbodyne by using the kits supplied by Tulip diagnostics (P) Ltd, India.

ALP was estimated by IFCC kinetic method by using Erba Mannheim reagent kits obtained from Transasia Bio-Medicals. Analysis was done on Erba Mannheim Chem -5 analyser.

\section{Statistical Analysis}

Data obtained from the investigations were analyzed and expressed as mean \pm SD. Statistical comparisons were performed by student ' $t$ ' test.

\section{Results}

In the present study, patients with rheumatoid arthritis and non -rheumatoid arthritis controls were in the age group of 35-65 years. Among the 54 patients with RA, 14 $(25.9 \%)$ were males and $40(74.1 \%)$ were females as shown in Table 1. The mean age of males and females in cases was 49.87 years and in controls was 48.31 years.

Table 1: Gender distribution and mean age of Non rheumatoid arthritis controls and Rheumatoid arthritis patients

\begin{tabular}{|l|c|c|c|}
\hline Groups & Males & Females & Mean age \\
\hline Non-rheumatoid arthritis controls & 27 & 27 & 49.87 \\
\hline Rheumatoid arthritis patients & 14 & 40 & 48.31 \\
\hline
\end{tabular}

Table 2 and Fig. 1 shows the Mean \pm SD of ADA \& ALP levels in serum of RA patients and the controls. As compared to the controls, serum ADA \& ALP levels were increased in cases and significant difference $(\mathrm{p}<0.001)$ was found between the two groups. 
Table 2: serum ADA \& ALP levels in Non rheumatoid arthritis controls and Rheumatoid arthritis patients

\begin{tabular}{|l|c|c|c|}
\hline Parameters & $\begin{array}{c}\text { NRA } \\
\text { mean } \pm \text { SD }\end{array}$ & $\begin{array}{c}\text { RA } \\
\text { mean } \pm \text { SD }\end{array}$ & p-value \\
\hline ADA & $11.19 \pm 1.802$ & $31.37 \pm 4.168$ & $\mathrm{P}<0.01, \mathrm{HS}$ \\
\hline ALP & $83.19 \pm 17.550$ & $145.17 \pm 15.868$ & $\mathrm{P}<0.01, \mathrm{HS}$ \\
\hline
\end{tabular}

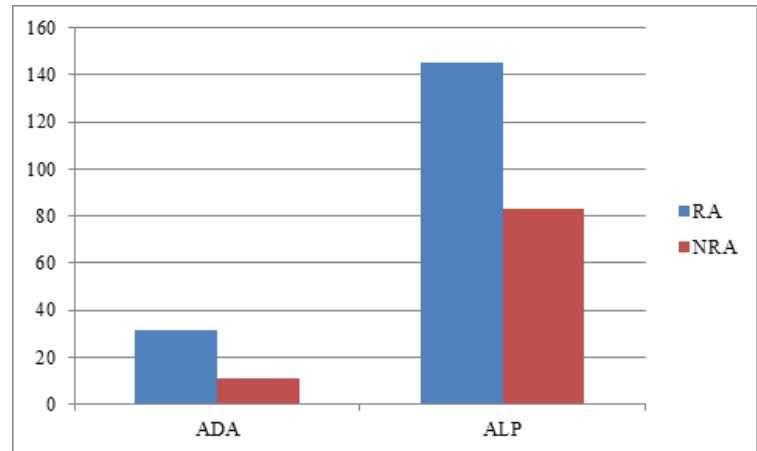

Fig. 1: Mean serum ADA \& ALP in RA \& NRA

Table 3 shows the Mean \pm SD of CRP \& RF levels in serum of RA patients and the controls. As compared to the controls, serum CRP \& RF were increased in cases and significant difference $(\mathrm{p}<0.001)$ was found between the two groups.

Table 3: serum RF, CRP levels in Non rheumatoid arthritis controls and Rheumatoid arthritis patients

\begin{tabular}{|l|c|c|c|}
\hline Parameters & $\begin{array}{c}\text { NRA } \\
\text { mean } \pm \text { SD }\end{array}$ & $\begin{array}{c}\text { RA } \\
\text { mean } \pm \text { SD }\end{array}$ & p-value \\
\hline CRP & $0.283 \pm 0.1161$ & $2.606 \pm 1.1612$ & $\mathrm{P}<0.01, \mathrm{HS}$ \\
\hline $\mathrm{RF}$ & $11.94 \pm 2.521$ & $35.74 \pm 5.944$ & $\mathrm{P}<0.01, \mathrm{HS}$ \\
\hline
\end{tabular}

\section{Discussion}

RA is likely to affect women approximately two times more than men $^{17}$ and $80 \%$ of people with RA develop signs and symptoms of the disease between $35 \& 50$ years of age. ${ }^{18}$ Our study also showed similar findings.

Pathogenesis of RA is still not fully understood, there is evidence that $\mathrm{CD} 4+\mathrm{T}$ cells play a central role in initiating, perpetuating and precipitating chronic inflammation in synovial tissue. ${ }^{19,20}$ Another role of activated CD4+T cells is stimulation of $\mathrm{B}$ cells to differentiate into plasma cells producing RF (Rheumatoid Factor) and other auto antibodies. ${ }^{21,22} \mathrm{ADA}$ is one of the most essential immune enzymes. Its function gives a clear picture of the immune status of the body. ${ }^{22,23}$ A close correlation has been found between the severity of inflammation and local increase in both expression and activity of ADA. ${ }^{24}$ ADA plays a crucial role in lymphocyte proliferation and differentiation ${ }^{25}$ and shows its highest activity in T- lymphocytes. ${ }^{26}$ The high plasma ADA activity might be due to abnormal T- lymphocyte responses or proliferation. ${ }^{24}$ The increased serum level of ADA is indicator of stimulation of cellular immunity. For instance, this condition can be seen in lymphoblastic leukemia, acute hepatitis, human immunodeficiency (HIV) virus infection, infectious mononucleosis, tuberculosis, pneumonia and rheumatoid arthritis. Some have suggested that the major source of the prevalent form of ADA (ADA2) in serum is the monocyte / macrophage cell system. ${ }^{27}$ The increase in serum ADA level in RA patients can be explained by immunity status changes. In this case, the ADA level reflects the monocyte/macrophage activity or turnover. $^{4}$ Many studies demonstrated the elevated serum level of ADA in RA patients. ${ }^{28-30}$

A study by Sari et al reported that the serum total ADA activity is associated with RA and may provide a useful adjunct to assess inflammation besides traditional indices. ${ }^{29}$ Similarly, Surekha Rani et al., also observed that measurement of ADA besides CRP levels helps in the better management RA patients. ${ }^{4}$ On the other hand, Haque SS and colleagues found significantly higher levels of ADA in RA patients compared to controls and a positive CRP test in a significant number of RA patients and 
reported that measuring ADA activity helps in a better understanding of some of the pathophysiological aspects of the diseas. ${ }^{31}$

Estimation of CRP has been suggested to be crucial for estimating short term changes in RA patients. ${ }^{32,33}$ Some studies have shown elevated CRP levels in patients with RA. ${ }^{34,35}$ This may be due to synthesis of CRP in liver triggered by pro inflammatory cytokines released from monocyte and macrophages. The pro inflammatory response leads to secretion of IL- $1 \beta$ and TNF $\alpha$ which further results in the release of Interleukin-6, a messenger cytokine which stimulates liver to secrete CRP. ${ }^{4}$

Our study has also observed a significant rise in serum CRP \& ADA levels in RA subjects as compared to controls which are in agreement with other studies.

In this study, serum ALP was found to be raised in patients of rheumatoid arthritis when compared to the healthy controls. The finding of raised ALP in this study is similar to the work done by several authors. ${ }^{36-38}$ The increase in ALP in rheumatoid arthritis has been attributed to osteoblastic activity indicating an increased bone turnover. It is known that promotion of disease activity induces more active bone resorption. Activated bone resorption is accompanied by concomitant bone formation and rise in serum ALP. ${ }^{14}$

Hepatic involvement in rheumatoid arthritis has been reported and liver is one of the organs affected by rheumatoid arthritis. The hepatic changes may be a response to chronic inflammatory disease.

\section{Conclusion}

There was a significant difference in the levels of ADA \& ALP activity between the RA patients and healthy controls which may indicate its usefulness in diagnosing the disease. During inflammation of RA, ADA is released in extracellular location, resulting in the activation of Cell Mediated Immunity. The biochemical alterations in rheumatoid arthritis observed in this study reflect on the pathogenesis of RA. The understanding of pathophysiology of rheumatoid arthritis may help open new therapeutic approaches in the management of rheumatoid arthritis. Therefore we conclude that serum ALP and ADA can also be used as a marker of disease activity in rheumatoid Arthritis.

\section{Limitations of the study \& Recommendations}

The sample size in our study is less. We have not estimated serum uric acid levels in RA patients. Interleukin-6 (IL-6) a pleiotropic cytokine which plays a pivotal role in the pathophysiology of RA was not estimated. Moreover, a large cross-sectional study needs to be done to conclude the fact.

\section{Acknowledgements}

It is our proud privilege to express profound sense of gratitude \& sincere thanks to all the participants and specially Managing director of Subbaiah Institute of Medical Sciences for their support to make this study successful which has been completed with logical and fruitful conclusion.

\section{Conflict of Interest}

No conflict of interest to disclose and no funding were received for this work.

\section{References}

1. Patel PK, Bhadoriya U; A survey on rheumatoid arthritis. Asian J Pharmacy Life Sci., 2011;1(3):312-7.

2. Silman AJ, Hochberg MC; Epidemiology of the Rheumatic Diseases. $2^{\text {nd }}$ edition, Oxford University Press, New York, 2001.

3. Devi SM, Balachandar V, Sasikala K, Manikantan P, Arun M, Ahammed SAKM et al.; Elevated rheumatoid factor (RF) from peripheral blood of patients with rheumatoid arthritis (RA) has altered chromosomes in Coimbatore population, South India. International Journal of Arthritis and Rheumatism, 2013;1(3):24-30.

4. Surekha rani H, G,Srikanth BM, Jharna P,Rao UR, Jyothy A.Serum ADA and C-reactive protein in rheumatoid arthritis.Int $\mathrm{J}$ Hum Genet.2006;6(3):195-8.

5. Vyas S, Sharma H, Vyas RK; Comparative Study of Adenosine Deaminase (ADA): Activity in the serum of rheumatoid arthritis and osteoarthritis patients. International Journal of Science and Research, 2013;4(3):908-10.

6. Aletaha D, Neogi T, Silman AJ, Funovits J, Felson DT, Bingham CO $3^{\text {rd }}$ et al.; 2010 Rheumatoid arthritis classification criteria: an American College of Rheumatology/European League against Rheumatism collaborative initiative. Arthritis and Rheumatism, 2010;62(9):2569-81.

7. Neogi T, Aletaha D, Silman AJ, Naden RL, Felson DT, Aggarwal R et al.; The 2010.

8. American College of Rheumatology/European League against Rheumatism classification criteria for rheumatoid arthritis: Phase 2 methodological report. Arthritis and Rheumatism, 2010;62(9):2582-91.

9. Van Ede AE, Laan RF, De Abreu RA, Stegeman AB, van de Putte LB. Purine enzymes in patients with rheumatoid arthritis treated with methotrexate. Ann Rheum Dis. 2002;61(12):1060-64.

10. Fox IH, Kelley WN. The role of adenosine and 2'-deoxyadenosine in mammalian cells. Annu Rev Biochem. 1978;47:655-86. 
11. Demir G, Borman P, Ayhan F, Ozgün T, Kaygısız F, Yilmez G. Serum Adenosine Deaminase Level is High But Not Related with Disease Activity Parameters in Patients with Rheumatoid Arthritis. Open Rheumatol J. 2014;8:24-28.

12. Aletaha D, Smolen J, Ward MM. Measuring function in rheumatoid arthritis: Identifying reversible and irreversible components. Arthritis Rheum. 2006;54(9):2784-92.

13. Molenaar TH,. Voskuyl AE, FamilianA, Mierlo GJ, Dijkmans BA, and Hack CE. Complement Activation in Patients With Rheumatoid Arthritis Mediated in Part by C-Reactive Protein. Arthritis \& Rheumatism.2001;44(5):997-1002.

14. Sambrook P N, Ansell B M,Foster S et al. Bone Turnover In Early Rheumatoid Arthritis I Biochemical And Kinetic Indexes. Ann Rheum Dis.1985;44:575-9.

15. Posen S. Alkaline Phosphatase. Ann Intern Med. 1967;183-203.

16. P.W. Thompson,B.J.Houghton,C.Clifford,D.D. Jones et al.Int Journal Of Medicine.Q.J Med 1990:76;869-879.

17. Arnett FC, Edworthy SM, Bloch DA, McShane DJ, Fries JF, Cooper NS, et al. The American Rheumatism Association 1987 revised criteria for the classification of rheumatoid arthritis. Arthritis Rheum. 1988;31(3):315-24.

18. Firestein GS (2009). Kelley's Textbook of Rheumatology, $8^{\text {th }}$ edition. Philadelphia Saunders Elsevier.

19. Michet C (1998). Update in the epidemiology of the rheumatic diseases. Curr Opin Rheumatol 10, 129-135.

20. Anderson, R.J; Rheumatoid arthritis, Clinical and laboratory Features. n: Keppel, J.H; Crofford, L.J; Ston, J.H.et al .Primer on the Rheumatic Disease. $12^{\text {th }}$ edit.Atlanta Georgia-Arthritis Foundation. 2001;218-25.

21. Kathleen B and Mason I, :Pathomechanisms in rheumatoid arthritis-time for a string theory? The Journal of Clinical Investigation 2006;116(4):869-71.

22. Helen, ch. Mansel, H. Siraj, M. and Neil, S. Joints and muscles. In: Essentials of clinical Immunology 5thed.Blackwell publishing.U.S.A.2006;180-3.

23. AL-Ubaide, A.H.; AL-Jeboori, T.I. \& Juma, A, S.ADA level in patients with hydatid disease (Echinococcus granulosis).Iraqi J Med Sci.2003;2(1):25-8.

24. Juma, A., AL-Jeboori, T.I., Tawfiq, M.S. \&Fadhil, R.S.: ADA Activity in the serum of patients with Schistosoma haematobium \& those with bladder carcinoma. Iraqi J Med Sci.2003;2(3):24-8.

25. Desrosiers MD, Cembrola KM, Fakir MJ, Stephens LA, Jama FM, Shameli A, et al. Adenosine deamination sustains dendritic cell activation in inflammation. $\mathbf{J}$ of Immunology 2007; 179:1884-92.

26. Hovi T, Smyth JF, Allison AC, Williams SC. Role of adenosine deaminase in lymphocyte proliferation. Clin Exp Immunol 1976;23:395403.

27. Sullivan JL, Oxborne WRA, Wedgewood RJ. Adenosine deaminase activity in lymphocytes. $\mathrm{Br}$ J Haematol 1977;37:157-58.
28. Ungerer JPJ, Oosthuizen HM, Blssbort SH, Vermaak WJH .Serum adenosine deaminase: Isoenzymes and diagnostic application. Clin Chem .1992;38,1322-26.

29. Nalesnik M, Nikolić JM, Jandrić S. Adenosine deaminase and $\mathrm{C}$-reactive protein in diagnosing and monitoring of rheumatoid arthritis. Med Glas Ljekkomore Zenicko dobojkantona .2011;8,1638.

30. Sari RA, Taysi S, Yilmaz Ö, Bakan N. Correlation of serum levels of adenosine deaminase activity and its isoenzymes with disease activity in rheumatoid arthritis. Clin Exp Rheumatol 2003;21:87-90.

31. Pallinti V, Ganesan N, Anbazhagan M, Rajashekhar G. Serum biochemical markers in rheumatoid arthritis. Indian J Biochem Biophys .2009;46:342-4.

32. Haque SS, Kumar S, Kumari R, Kumar U, Saran A, Tanweeruddin M. Evaluation of Biochemical marker for the diagnosis of Rheumatoid arthritis. J Health Sciences 2014;04(01):187-92.

33. Karsdal MA, Woodworth T, Henriksen K, Maksymowych WP, Genant H, VergnaudP, et al. Biochemical markers of ongoing joint damage in rheumatoid arthritis-current and future applications, limitations and opportunities. Arthritis Res Ther 2011;13 (2):215.

34. Matsui T, Kuga Y, Kaneko A, Nishino J, Eto Y, Chiba N, et al. Disease Activity Score 28 (DAS28) using C-reactive protein underestimates disease activity and Overestimates EULAR response criteria compared with DAS28 using erythrocyte sedimentation rate in a large observational cohort of rheumatoid arthritis patients in Japan. Ann Rheum Dis 2007;66(9):1221-6.

35. Klimek E, Skalska A, Kwasny-Krochin B,Surdacki A, Sulicka J, Korkosz M, et al. Differential associations of inflammatory and endothelial biomarkers with disease activity in rheumatoid arthritis of short duration. Mediators Inflamm 2014;2014:681635.

36. Shrivastava AK, Singh HV, Raizada A,Singh SK, Pandey A, Singh N, et al. Inflammatory markers in patients with rheumatoid arthritis. Allergol Immunopathol(Madr) 2015;43(1):81-87.

37. Aida S.Relation Between Alkaline Phosphatase Isoenzymes And Disease Activity In Rheumatoid Arthritis.Acta Med Biol 1992;40:79-83.

38. Kendall M J,Cockel R,Hawkins Cf.Raised Alkaline Phosphatase In Rheumatoid Arthritis.An Index Of Liver Dysfunction.Ann Rheum Dis 1970;537-40.

39. Rosalki S B,Foo Ay,Tanner Pas,Serum Gamma Glutamyl Transferase And Alkaline Phosphatase In Rheumatoid Arthritis.J Clin Pathol 1982;35:1395. 